\title{
EFFECTS OF FABP2 ALA54THR GENE POLYMORPHISM ON OBESITY AND METABOLIC SYNDROME IN MIDDLE-AGED KOREAN WOMEN WITH ABDOMINAL OBESITY
}

\author{
Tae-Kyung Han ${ }^{1}$, Wi-Young So ${ }^{2}$ \\ ${ }^{1}$ Physical Education, College of Art and Physical Education, Andong National University, Andong, Republic of Korea \\ ${ }^{2}$ Sports and Health Care, College of Humanities and Arts, Korea National University of Transportation, Chungju-si, Republic of Korea
}

\begin{abstract}
SUMMARY
Objectives: Asians (including Chinese, Japanese and Koreans), who generally have a relatively smaller body size and a lower mean body mass index (BMI), have a relatively higher risk of developing android-type obesity than westerners. Substitution of alanine for threonine (Ala54Thr) on the FABP2 gene (rs 1799883) is related to insulin resistance and obesity. However, few studies have examined this substitution in Koreans, and the number of Korean subjects in those studies is limited. For this reason, we investigated the differences between the FABP2 Ala54Thr polymorphism and obesity, hemodynamic variables, blood lipid profile results, and insulin resistance among middle-aged Korean women with abdominal obesity.

Methods: We studied 243 middle-aged community-dwelling Korean women with abdominal obesity from Gyeonggi Province, Republic of Korea, who had no history of taking chronic medications. We examined each subject $(n=243)$ for the presence of FABP2 Ala54Thr polymorphism using polymerase chain reaction-restriction fragment length polymorphism (PCR-RFLP). Subjects were also examined for obesity hemodynamic variables $(n=243)$, lipid profiles $(n=142)$, and insulin resistance $(n=142)$.

Results: Of the 243 subjects, 117 had AA ("normal") homozygotic genotype, 100 had AT heterozygotic genotype, and 26 had TT homozygotic genotype for the FABP2 Ala54Thr polymorphism. The AT heterozygotic individuals had a significantly higher mean waist-to-hip ratio, abdominal fat area, and visceral fat area than individuals with other genotypes. TT homozygotic individuals had higher mean triglyceride and fasting glucose levels than individuals with other genotypes.

Conclusions: The results of this study show that the FABP2 Ala54Thr polymorphism was associated with central obesity and obesity-related metabolic syndrome among middle-aged Korean women.
\end{abstract}

Key words: abdominal obesity, fatty acid binding protein-2, fatty acid binding protein-2 polymorphism, insulin resistance, middle-aged women

Address for correspondence: Wi-Young So, Sports and Health Care, College of Humanities and Arts, Korea National University of Transportation, 50 Daehak-ro, Chungju-si, Chungbuk 380-702, Republic of Korea. E-mail: wowso@ut.ac.kr

https://doi.org/10.21101/cejph.a5077

\section{INTRODUCTION}

In 2000, approximately 1.2 billion people worldwide were overweight or obese, and 2.5 million deaths were caused by obesity-related illnesses; without appropriate intervention, this number could have reached 5 million (1). Obesity is classified into android-type obesity (apple-shaped obesity) and gynoidtype obesity (pear-shaped obesity). In android-type obesity, the fat mass occurs in the abdominal area and is more likely to be associated with metabolic syndrome and insulin resistance than gynoid-type obesity, in which the fat mass usually accumulates in the thigh area $(2,3)$.

Interestingly, Asians (including Chinese, Japanese and Koreans), who generally have a relatively smaller body size and a lower mean body mass index (BMI), have a relatively higher risk of developing android-type obesity than westerners $(4,5)$. Therefore, in the absence of treatment, Asians, including Koreans, have a higher risk of disorders associated with obesity-related metabolic syndrome, including diabetes, dyslipidemia, hypertension, cardiovascular disease, and cancer (6-8).

Metabolic syndrome is associated with insulin resistance; patients with metabolic syndrome often have poor dietary habits and a sedentary lifestyle. Non-insulin-dependent diabetes and obesity have a genetic link (9). Considerable effort has been made to identify the genes associated with insulin resistance. Only one gene affects insulin sensitivity (10). Current candidate genes include the insulin receptor substrate-1 (IRS-1), $\beta 3$-adrenergic receptor ( $\beta 3$-AR), uncoupling protein-1 (UCP-1), glucose transporter (GLUT), and fatty acid binding protein-2 (FABP2) (11-13). Pima Indians suggest that the $F A B P 2$ gene is associated with insulin sensitivity (14).

To date, nine FABP genes have been shown to be expressed in various tissue types: a 1-kilobase $(\mathrm{kb})$ sequence upstream from the start codon in the regulatory region, three indel polymorphisms, and four single nucleotide polymorphisms (SNPs). One of the nine $F A B P$ genes, the $F A B P 2$ gene $(3.4 \mathrm{~kb})$, is located on chromosome 
4q28-31 and has four exons (700 base pairs (bp) and three introns (2,650 bp) (15). In FABP2, substitution of alanine for threonine (Ala54Thr, rs 1799883), resulting from substitution of adenine for guanine, is associated with insulin resistance (16). FABP2, a relatively small protein (15 kilodalton), is involved in the absorption of fatty acids and intracellular transportation and is widely distributed in epithelial cells of the villi in the small intestine (17, 18). The FABP2 for long-chain fatty acids is doubled when in $F A B P 2$ gene has an Ala54Thr polymorphism (16). This increase in fat absorption and free fatty acids (FFAs) may cause insulin resistance by increasing intracellular oxidation (16).

The Ala54Thr polymorphism increases triglyceride (TG) secretion and free fatty acid transport in vitro (19). Moreover, the Thr54 allele is associated with a higher level of fasting insulin, insulin resistance, and 2-h blood glucose level (20). Furthermore, with excess absorption of fatty acids, the thr54 variant considers skeletal muscles a priority and uses fatty acids rather than glucose for energy; this leads to an increase in glucose levels (21).

Studies of Japanese, Pima Indians, and some Caucasians found that FABP2 Ala54Thr polymorphism is associated with insulin resistance, but studies among populations from England, Finland, Wales, and some European countries found no association, suggesting differences among races $(10,14,16,22,23)$. Previous studies on $F A B P 2$ polymorphisms and energy metabolism in the body found no differences in BMI, blood lipid concentrations, or fasting glucose levels between individuals with FABP2 Ala54Thr polymorphism and those with other genotypes. Homeostasis model assessment (HOMA) found that basal insulin concentrations and insulin resistance index are both higher in the presence of the FABP2 Ala54Thr polymorphism $(24,25)$. Although there are no differences in metabolic rates among individuals with these alleles, the Thr54 allele results in a significantly higher level of fat oxidation than the Ala54 allele, indicating that the FABP2 Ala54Thr polymorphism may cause insulin resistance through changes in fat metabolism among Koreans (25). However, few studies have examined changes in fat metabolism in Koreans, and studies that evaluated Koreans had few subjects. Therefore, this study aimed to examine the differences between FABP2 Ala54Thr polymorphism and obesity variables (weight, waist circumference, waist-to-hip ratio, BMI, percent body fat, total abdominal area, visceral area, subcutaneous area, visceral area/subcutaneous area ratio, and maximum volume of oxygen consumed), hemodynamic variables (systolic blood pressure, diastolic blood pressure, mean arterial pressure, heart rate, and cardiac stress), blood lipid profile, and insulin resistance among middle-aged Korean women with abdominal obesity.

\section{MATERIALS AND METHODS}

\section{Participants}

We recorded the age, history of hormone replacement therapy, physical activity level, waist circumference, weight status, smoking status, and current drug use among participants of a health promotion programme from September 2006 to December 2007 in Gyeonggi Province, Republic of Korea. In this study, 243 middle-aged women who had a waist circumference $>80 \mathrm{~cm}$ were enrolled (1). Because of mechanical errors, blood samples of 101 study subjects were not examined for lipid profile and insulin resistance, but were examined for FABP2 Ala54Thr polymorphism. Therefore, we examined 243 subjects for the presence of the FABP2 Ala54Thr polymorphism using polymerase chain reaction-restriction fragment length polymorphism (PCR-RFLP), obesity variables, and hemodynamic variables, but studied only 142 subjects for blood lipid profile and insulin resistance.

All participants gave informed consent prior to participation in this study. This study was approved by the institutional ethics review board of the College of Sport Science, Sungkyunkwan University, and was conducted according to the principles of the Helsinki Declaration.

\section{FABP2 Polymorphism Analysis}

A fasting venous blood sample was obtained from each subject. The DNA was extracted using DNA extraction kit (Qiagen, Hilden, Germany). PCR-RFLP (26) was then conducted using the GeneAmp PCR System 9700 (Applied Biosystems, Foster City, CA, USA) with $2 \mu \mathrm{L}$ of DNA template, $15 \mu \mathrm{L}$ of $2 \times$ PCR master mix (Promega, Madison, WI, USA), $0.25 \mu \mathrm{L}$ of sense primer (5'-CTACCGAGTTTTCTTCCCACC-3'), $0.25 \mu \mathrm{L}$ of antisense primer ( $5^{\prime}$-AATTAAACCATCCAATGAAATAGAGC-3'), and $12.5 \mu \mathrm{L}$ of distilled water. Fragments were amplified as follows: 5 min of denaturation at $94^{\circ} \mathrm{C} ; 25$ cycles of denaturation for 30 s at $94^{\circ} \mathrm{C}$, annealing for $30 \mathrm{~s}$ at $55^{\circ} \mathrm{C}$, extension for $30 \mathrm{~s}$ at $72^{\circ} \mathrm{C}$, and a final extension for $30 \mathrm{~s}$ at $72^{\circ} \mathrm{C}$. Four units of the restriction enzyme HhaI (New England BioLabs, Beverly, MA, USA) was added to the PCR product and incubated for $1.5 \mathrm{~h}$ at $37^{\circ} \mathrm{C}$. Electrophoresis of the sample was conducted at 85 volts for 120 min on $2 \%$ agarose gel and stained with ethidium bromide. Different DNA fragment sizes were observed: two bands at 200 and $175 \mathrm{bp}$, indicating the AA ("normal") genotype; three bands at 375, 200, and 175 bp indicating the AT genotypes; and a single band at $375 \mathrm{bp}$ indicating the TT genotype (Fig. 1).

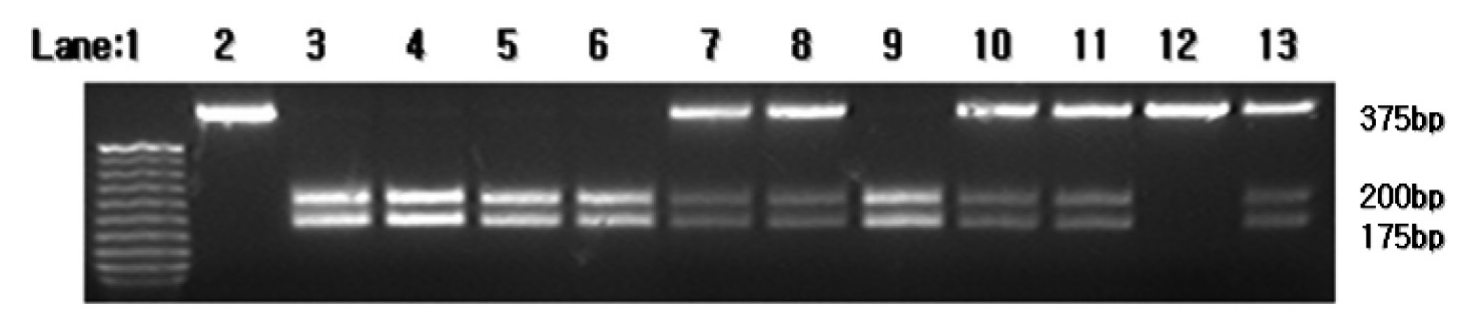

Fig. 1. Illustration of FABP2 gene polymorphism. Lane 1: 25-bp marker; lanes 3-5, 6, and 9: Ala/Ala; lanes 7, 8, 10, 11, and 13: Ala/Thr; lanes 2 and 12: Thr/Thr. 


\section{BMI and Blood Pressure}

Heights and weights were determined for each study subject and BMI was calculated $\mathrm{kg} / \mathrm{m}^{2}$ as the weight in kilograms divided by the height in meter squared. The percent body fat was measured using an eight-polar bioelectrical impedance analysis (X-Scan Body Composition Analyzer, JAWON Medical Co., Seoul, Korea) $(27,28)$. Waist circumference at the umbilicus and hip circumference at the widest area between the superior and inferior iliac crests were measured using a measuring tape and the waist-to-hip ratio (WHR) was then calculated. Abdominal, subcutaneous, and visceral fat areas were measured at the Korean Health Management Association, Suwon City, Korea by computerized tomography at the fourth lumbar level (SCT-7800TE; SHIMADZU, Kyoto, Japan) (29, 30). Resting blood pressure was measured twice at 5 min interval using an automatic sphygmomanometer (JAWON Medical Co., Seoul, Korea), and the mean value was then calculated and recorded. Cardiac stress (index) was defined as systolic blood pressure $(\mathrm{mm} \mathrm{Hg}) \times$ heart rate (beats per minute)

\section{Blood and Blood Lipid Profile}

Venous blood was collected from brachial veins after fasting for 10-12 h. Collected blood was immediately centrifuged, and the serum was then stored at $-80^{\circ} \mathrm{C}$ until use. The serum samples were examined for total cholesterol (TC), high-density lipoprotein cholesterol (HDL-C), and TGs using a Vitros DT60II Chemistry System (Johnson \& Johnson, NY, USA). Blood HDL-C levels were analyzed following the precipitation of cholesterol with apolipoprotein B using magnesium chloride and dextran sulfate. Low-density lipoprotein cholesterol (LDL-C) levels were calculated using the following formula: $\mathrm{LDL}-\mathrm{C}=\mathrm{TC}-(\mathrm{HDL}-$ $\mathrm{C}+(\mathrm{TG} / 5))(31)$.

\section{Oral Glucose Tolerance Test}

The Oral Glucose Tolerance Test (OGTT) was performed on each subject as follows: a 21-gauge polyethylene catheter was inserted in the brachial vein, and $75 \mathrm{~g}$ of glucose was injected (32). Venous blood was collected $10 \mathrm{~min}$ before the glucose injection and then at 30,60, 90, and $120 \mathrm{~min}$ after injection. The collected venous blood was centrifuged and stored at $-80^{\circ} \mathrm{C}$. Blood glucose levels were analyzed using the Vitros DT60II Chemistry System. An insulin level was also measured using a human insulin enzymelinked immunosorbent assay kit (DSL, TX, USA). For samples were collected at $120 \mathrm{~min}$ after the glucose injection, and the area under the curve (AUC) was calculated using the following formula (33):

$\mathrm{AUC}=((\mathrm{M} 2+\mathrm{M} 1) / 2)+((\mathrm{M} 3+\mathrm{M} 2) / 2)+((\mathrm{M} 4+\mathrm{M} 3) / 2)+((\mathrm{M} 5+\mathrm{M} 4) / 2)$,

where M1 is the fasting glucose level, M2 is the glucose level at $30 \mathrm{~min}, \mathrm{M} 3$ is the glucose level at $60 \mathrm{~min}, \mathrm{M} 4$ is the glucose level at $90 \mathrm{~min}$, and M5 is the glucose level at $120 \mathrm{~min}$.
The HOMA index was calculated from the fasting serum glucose and insulin levels using the following formula (34):

HOMA index $=($ glucose level $(\mathrm{mM}) \times$ insulin level $(\mu \mathrm{U} / \mathrm{mL})) / 22.5$.

\section{Cardiorespiratory Fitness}

Cardiorespiratory fitness (maximal oxygen consumption, $\mathrm{VO}_{2} \max$ ) was measured by a treadmill exercise test at $1.7 \mathrm{mph}$ and a $10 \%$ of grade using Bruce Protocol (35) with an increase of $0.8-0.9 \mathrm{mph}$ and $2 \%$ of grade every $3 \mathrm{~min}$, and breath-bybreath type was applied using gas analyzer (TrueOne Metabolic Cart; Parvo Medics, Sandy, UT, USA) and a wireless heart rate analyzer (Polar a5, Polar, Finland). Oxygen consumption per minute was measured at $85 \%$ of the maximum predicted heart rate to determine cardiorespiratory fitness (36). Cardiorespiratory fitness followed the recommendations of the book Advanced Fitness Assessment and Exercise Prescription (37).

\section{Statistical Analysis}

All data were expressed as means \pm standard deviations and were analyzed by descriptive statistics. Test of normality for all measured values was conducted using one-sample Kolmogorov-Smirnov Test. Homoscedasticity test was conducted using Levene variance F-test. In this study, all variables at $p>0.05$ were accepted appropriate for model. Comparisons of each variable with respect to the FABP2 Ala$54 \mathrm{Thr}$ polymorphisms were made using one-way analysis of variance and Tukey's post-hoc testing. Statistical calculations were performed using SPSS, version 18.0 (Chicago, IL, USA). Statistical significance was set at $\mathrm{p}<0.05$.

\section{RESULTS}

\section{Association of FABP2 Ala54Thr Polymorphism}

Of the 243 participants (48.1\%), 117 had the AA genotype ("normal") on PCR-RFLP, 100 (41.2\%) had the AT genotype, and $26(10.7 \%)$ had the TT genotype (Table 1$)$. The relative incidences of the $\mathrm{A}$ and $\mathrm{T}$ alleles were $68.7 \%$ and $33.3 \%$, respectively.

\section{Differences between $F A B P 2$ Ala54Thr Genotypes and Obesity Factors and Cardiorespiratory Fitness}

The WHR, total abdominal (TA) area, and visceral fat area were statistically significantly associated with distribution of FABP2 Ala54Thr genotypes $(\mathrm{p}<0.05)$. However, there were no statistically significant differences in age, weight, BMI, percent body fat, subcutaneous area, visceral fat area/subcutaneous fat area, and $\mathrm{VO}_{2} \max (\mathrm{p}>0.05)$ (Table 2).

Table 1. Relative frequencies of FABP2 Ala54Thr genotypes in study population $(N=243)$

\begin{tabular}{|l|c|c|c|c|c|}
\hline \multirow{2}{*}{ Independent/Dependent } & \multicolumn{3}{|c|}{ Genotype frequency } & \multicolumn{2}{c|}{ Allele frequency } \\
\cline { 2 - 6 } & Ala/Ala & Ala/Thr & Thr/Thr & A & T \\
\hline Total & $117(48.1 \%)$ & $100(41.2 \%)$ & $26(10.7 \%)$ & $334(68.7 \%)$ & $152(31.3 \%)$ \\
\hline
\end{tabular}


Table 2. Comparison of baseline values in obesity factors and cardiorespiratory fitness among FABP2 Ala54Thr genotypes

\begin{tabular}{|c|c|c|c|c|}
\hline \multirow{2}{*}{ Independent/Dependent } & \multicolumn{3}{|c|}{ Genotype } & \multirow{2}{*}{ p-value } \\
\hline & Ala/Ala $(n=117)$ & Ala/Thr $(n=100)$ & $\operatorname{Thr} / \operatorname{Thr}(\mathrm{n}=26)$ & \\
\hline Age (years) & $45.9 \pm 7.2$ & $47.1 \pm 7.6$ & $48.6 \pm 9.2$ & 0.194 \\
\hline Weight (kg) & $64.1 \pm 7.2$ & $64.1 \pm 7.2$ & $64.1 \pm 6.7$ & 0.993 \\
\hline WHR (\%) & $0.93 \pm 0.05^{\#}$ & $0.95 \pm 0.05^{\#}$ & $0.95 \pm 0.04^{\#}$ & $0.017^{*}$ \\
\hline BMI $\left(\mathrm{kg} / \mathrm{m}^{2}\right)$ & $25.6 \pm 2.6$ & $25.8 \pm 2.6$ & $26.1 \pm 2.5$ & 0.701 \\
\hline Body fat (\%) & $33.2 \pm 2.9$ & $33.3 \pm 3.0$ & $33.6 \pm 3.3$ & 0.870 \\
\hline TA area $\left(\mathrm{mm}^{2}\right)$ & $48035.2 \pm 5796.8^{\# \#}$ & $52929.3 \pm 6577.9^{\# \#}$ & $48722.2 \pm 10135.2$ & $0.009^{* *}$ \\
\hline Visceral fat area $\left(\mathrm{mm}^{2}\right)$ & $8796.9 \pm 3491.6$ & $10115.1 \pm 3204.9^{\ldots \#}$ & $6693.3 \pm 1262.4^{\ldots \ldots}$ & $0.014^{*}$ \\
\hline Subcutaneous fat area $\left(\mathrm{mm}^{2}\right)$ & $19844.3 \pm 4906.0$ & $19993.9 \pm 4386.8$ & $18866.4 \pm 4762.7$ & 0.835 \\
\hline V/S ratio & $0.46 \pm 0.18$ & $0.52 \pm 0.20$ & $0.37 \pm 0.09$ & 0.085 \\
\hline $\mathrm{VO}_{2} \max (\mathrm{mL} / \mathrm{min} / \mathrm{kg})$ & $26.5 \pm 4.3$ & $26.7 \pm 5.6$ & $25.8 \pm 5.4$ & 0.713 \\
\hline
\end{tabular}

WHR - waist-to-hip ratio; BMI - body mass index; TA area - total abdominal area; V/S ratio - visceral fat area/subcutaneous fat area. Cardiorespiratory fitness was measured as the maximum volume of oxygen consumption $\left(\mathrm{VO}_{2} \mathrm{max}\right)$ during graded treadmill exercise.

${ }^{*} p<0.05,{ }^{* *} p<0.01$, one-way analysis of variance

$\mathrm{p}<0.05,{ }^{\# A l a / A l a}<\mathrm{Ala} / \mathrm{Thr}, \mathrm{Thr} / \mathrm{Thr} ;{ }^{*} \mathrm{Ala} / \mathrm{Ala}<\mathrm{Ala} / \mathrm{Thr} ;{ }^{\# \#} \mathrm{Ala} / \mathrm{Thr}>\mathrm{Thr} / \mathrm{Thr} ;$ Tukey's post-hoc testing

Differences between $F A B P 2$ Ala54Thr Genotypes and Blood Pressure, Heart Rate and Cardiac Stress

The systolic blood pressure showed statistically significant differences among FABP2 Ala54Thr genotypes $(\mathrm{p}<0.05)$. However, there were no statistically significant differences in diastolic blood pressure, mean arterial pressure, heart rate, and cardiac stress $(\mathrm{p}>0.05)($ Table 3$)$.
Differences between FABP2 Ala54Thr Genotypes and Blood Lipid Profiles and Insulin Resistance Markers

The TG and glucose showed statistically significant differences among FABP2 Ala54Thr genotypes $(\mathrm{p}<0.05)$. However, there were no statistically significant differences in TC, LDL-C, HDL-C, insulin, and HOMA ( $p>0.05$ ) (Table 4).

Table 3. Comparison of baseline values in blood pressure, heart rate and cardiac stress among FABP2 Ala54Thr genotypes

\begin{tabular}{|l|c|c|c|c|}
\hline \multirow{2}{*}{ Independent/Dependent } & \multicolumn{3}{|c|}{ Genotype } & \multirow{2}{*}{ p-value } \\
\cline { 2 - 5 } & Ala/Ala $(\mathbf{n}=117)$ & Ala/Thr $(\mathbf{n = 1 0 0})$ & Thr/Thr $(\mathbf{n = 2 6 )}$ & $0.019^{*}$ \\
\hline SBP $(\mathrm{mm} \mathrm{Hg})$ & $114.6 \pm 14.5^{\#}$ & $119.9 \pm 14.0^{\#}$ & $117.3 \pm 10.2$ & 0.235 \\
\hline DBP $(\mathrm{mm} \mathrm{Hg})$ & $70.8 \pm 10.1$ & $73.1 \pm 10.1$ & $72.1 \pm 69.2$ & 0.701 \\
\hline MAP $(\mathrm{mm} \mathrm{Hg})$ & $84.8 \pm 11.2$ & $88.1 \pm 11.0$ & $87.4 \pm 8.8$ & 0.391 \\
\hline HR $(\mathrm{bpm})$ & $73.7 \pm 10.4$ & $71.9 \pm 10.7$ & $74.1 \pm 11.3$ & 0.527 \\
\hline Cardiac stress (index) & $8422.4 \pm 1824.9$ & $8638.6 \pm 1779.9$ & $8853.0 \pm 1546.7$ & \\
\hline
\end{tabular}

SBP - systolic blood pressure; DBP - diastolic blood pressure; MAP - mean arterial pressure; HR - heart rate; cardiac stress (index) = systolic blood pressure $(\mathrm{mmHg})$ $x$ heart rate $(\mathrm{bpm})$

${ }^{*} p<0.05$, one-way analysis of variance

$\mathrm{p}<0.05,{ }^{\#}$ Ala/Ala $<$ Ala/Thr, Tukey's post-hoc testing

Table 4. Comparison of baseline values in blood lipid levels and insulin resistance markers among FABP2 Ala54Thr genotypes

\begin{tabular}{|c|c|c|c|c|}
\hline \multirow{2}{*}{ Independent/Dependent } & \multicolumn{3}{|c|}{ Genotype } & \multirow{2}{*}{$\mathrm{p}$-value } \\
\hline & Ala/Ala $(n=72)$ & Ala/Thr $(n=57)$ & $\operatorname{Thr} / \operatorname{Thr}(n=13)$ & \\
\hline $\mathrm{TC}(\mathrm{mg} / \mathrm{dL})$ & $198.3 \pm 41.2$ & $192.9 \pm 42.6$ & $204.2 \pm 35.2$ & 0.434 \\
\hline LDLC (mg/dL) & $134.8 \pm 37.9$ & $127.6 \pm 32.4$ & $136.9 \pm 36.1$ & 0.464 \\
\hline $\mathrm{HDLC}(\mathrm{mg} / \mathrm{dL})$ & $41.6 \pm 11.4$ & $42.2 \pm 14.1$ & $38.8 \pm 9.0$ & 0.678 \\
\hline $\mathrm{TG}(\mathrm{mg} / \mathrm{dL})$ & $111.3 \pm 37.9^{\#}$ & $106.0 \pm 46.6$ & $142.2 \pm 65.3^{\#}$ & $0.026^{*}$ \\
\hline Glucose (mg/dL) & $97.0 \pm 15.6$ & $95.0 \pm 16.5^{\#}$ & $104.1 \pm 18.4^{\#}$ & $0.044^{*}$ \\
\hline Insulin $(\mu \mathrm{U} / \mathrm{mL})$ & $6.5 \pm 3.3$ & $7.0 \pm 3.8$ & $7.0 \pm 3.1$ & 0.765 \\
\hline HOMA (index) & $1.5 \pm 0.8$ & $1.6 \pm 0.9$ & $1.8 \pm 1$ & 0.338 \\
\hline
\end{tabular}

TC - total cholesterol; LDLC - low density lipoprotein cholesterol; HDLC - high density lipoprotein cholesterol; TG - triglyceride; HOMA index = $(\mathrm{glucose}$ [mM] $\times$ insulin $[\mu \mathrm{U} / \mathrm{mL}]) / 22.5$

${ }^{*} \mathrm{p}<0.05$, one-way analysis of variance

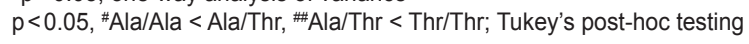




\section{DISCUSSION}

Obesity and its negative consequences are rapidly increasing worldwide. Genetic studies must concentrate on polymorphisms in the gene encoding $F A B P$, a protein involved in fat synthesis and metabolism, to identify factors that are correlated with obesity. The absorption of fat is one of the most important factors underlying metabolic syndrome. Polymorphisms in the intestinal FABP promoter, resulting in transcriptional activation, lead to changes in body composition, and a missense polymorphism in codon 54(Ala/Thr) has been linked to insulin resistance (38). FABP2 Ala54Thr polymorphism increases the absorption of fatty acids via food intake; indeed, FABP2 harbouring the Thr54 allele has twice the affinity for fatty acids compared with $F A B P 2$ harbouring the Ala54 allele. This polymorphism inhibits insulin activation by increasing fatty acid oxidation $(16,39)$.

Thus, in this study, we investigated the genetic influence of FABP2 Ala54Thr on obesity indices, hemodynamic variables, and insulin resistance in disease-free, middle-aged Korean women with abdominal obesity and a waist circumference greater than $80 \mathrm{~cm}$. Based on the genetic analysis of FABP2 in 243 women, we found that 117 women had the AA homozygotic genotype, 100 had the AT heterozygotic genotype, and 26 had the TT homozygotic genotype. Of these, the relative frequencies of A and $\mathrm{T}$ alleles were $68.7 \%$ and $33.3 \%$, respectively, similar to the frequencies seen in Pima Indiana (29\% T), Caucasian (31\% T), and Japanese $(35 \% \mathrm{~T})$ populations $(16,23)$. The relative frequency of FABP2 Ala54Thr polymorphisms in in our study showed the Hardy-Weinberg equilibrium, indicating that these patients were a representative sample of the population.

The Ala54Thr polymorphism in FABP2 has been shown to be associated with high BMI and percent body fat in Canadian Indians (40) and excessive accumulation of intra-abdominal fat in Japanese men (23). Furthermore, obesity index-related genetic sensitivity has been linked to FABP2 Ala54Thr polymorphism, as reported by Takakura et al. (41) and Albala et al. (42). Based on these previous studies, we expected to observe a correlation between total obesity indices and the FABP2 genotype. However, we did not observe significant differences in weight, BMI, percent body fat, or waist circumference among the FABP2 genotypes, as reported in previous studies $(15,26,43-44)$. To account for this discrepancy, Yun et al. (25) examined the relationship between resting metabolic rate (RMR) and the FABP2 Ala54Thr polymorphism in Korean men and found no difference in the RMR among FABP2 genotypes. However, Takakura et al. suggested that the Thr54 allele increases the obesity rate by lowering the RMR (41); thus, the results of studies on FABP2 Ala54Thr polymorphism and obesity are inconsistent and vary depending on the race, ethnicity, and characteristics of the participants.

In our study, we found no genetic link between the FABP2 Ala54Thr polymorphism and weight, percent body fat, or BMI in Korean women with abdominal obesity. However, individuals with the FABP2 AT heterozygotic genotype exhibited significantly higher central obesity indices, except for waist circumference, such as WHR, whole-abdominal area, and visceral fat. In other words, increases in WHR, whole-abdominal area, and visceral fat area in individuals with the Thr allele carriers were significantly larger than those in individuals with the AA homozygotic genotype, suggesting that the polymorphism in $F A B P 2$ was an important factor affecting genetic sensitivity to central obesity in middle-aged Korean women with abdominal obesity. When examining $\mathrm{VO}_{2}$ max per minute during the graded treadmill exercise, a predictor of cardiorespiratory fitness, we found no association between the FABP2 Ala54Thr polymorphism and cardiorespiratory fitness, as suggested by Weiss et al. (15).

Then, we examined the role of FABP2 Ala54Thr polymorphism in determining an individual's predisposition for hypertension by regression, after accounting for the increased systolic blood pressure in individuals with the TT homozygotic genotype and individual differences in age and body composition (weight, BMI, percent body fat, and WHR). Although not statistically significant, systolic blood pressure was positively associated with waist circumference. This indicated that the FABP2 Ala54Thr polymorphism was associated with a relatively higher risk of hypertension in middle-aged Korean women with abdominal obesity. Although previous studies have not reported an association between the FABP2 Ala54Thr polymorphism and hypertension, individuals with the Thr54 allele were assumed to have significantly higher blood TG and glucose levels, vessel elasticity, secretion of related proteins, and secretion of cytokines, causing vessel inflammation and subsequent increases in other cardiovascular factors (45-46), predisposing such individuals to obesity. In a study by Georgopoulos et al. (47), the Veterans Affairs HDL Intervention Trial compared dyslipidemia between men with or without type 2 diabetes. They found that the Thr54 polymorphism is associated with a 2- to 3.5-fold higher risk of cardiovascular disease in men with type 2 diabetes than in men without diabetes.

Baier et al. (16) conducted an OGTT in 760 Pima Indians and found that the FABP2 Ala54Thr polymorphism was significantly associated with insulin resistance and in vitro data also suggested that $F A B P 2$ containing Thr54 had a two-fold increase in affinity for long-chain fatty acids than FABP2 containing Ala54. Thus, Thr54 increases the absorption of fatty acids in the intestinal canal. Consequently, excessive release of fatty acids and increased insulin resistance are induced by systemic circulation and excessive influx of fatty acids in peripheral tissue. Similarly, Mitchell et al. (48) conducted an OGTT in Mexican-American individuals and reported that the FABP2 Thr54 allele increased insulin secretion at $120 \mathrm{~min}$ and significantly increased the risk of insulin resistance based on the HOMA index. However, there was no association between fasting insulin or HOMA index and FABP2 genotype among European populations in England or Finland (49, 50).

Nevertheless, our study had some limitations. First, the study lacked statistical power because of the inadequate number of participants and because blood samples from only a portion of the study population were examined to determine the associations between genetic or environmental factors and between the FABP2 Ala54Thr polymorphism and obesity. The inclusion of more participants would likely reveal a significant relationship between the FABP2 Ala54Thr polymorphism and obesity. Second, although other characteristics of the study participants, e.g., proportion of obese participants, diabetes, history of heart disease, age, or medications taken may have affected the results, we did not control for these variables. This may have biased the results. Third, this study did not include a control (nonobese) group; it is difficult to determine whether the polymorphism affected the development of central obesity in a homogeneous population because variations in the parameters were limited. Fourth, this 
study did not investigate dietary intake. However, we believe that this study is valuable because it focused on a specific group Korean middle-aged women with abdominal obesity and showed that FABP2 Ala54Thr polymorphism was associated with central obesity indices, such as WHR, total abdominal area, visceral fat, systolic blood pressure, blood TG, and glucose levels.

\section{CONCLUSION}

The results in this study showed that the FABP2 Ala54Thr polymorphism increased the risk of central obesity and obesityrelated metabolic syndrome in Korean middle-aged women.

\section{Acknowledgement}

This work was supported by a grant from 2016 Research Funds of Andong National University.

\section{Conflict of Interests}

None declared

\section{REFERENCES}

1. WHO; IASO; IOTF. The Asia-Pacific perspective: redefining obesity and its treatment. Health Communications Australia; 2000.

2. Kang HS, Gutin B, Barbeau P, Litaker MS, Allison J, Le NA. Low-density lipoprotein particle size, central obesity, cardiovascular fitness, and insulin resistance syndrome markers in obese youths. Int J Obes Relat Metab Disord. 2002;26(8):1030-5.

3. Vega GL. Obesity and the metabolic syndrome. Minerva Endocrinol. 2004;29(2):47-54.

4. He W, Zhang S, Song A, Yang M, Jiao J, Allison DB, et al. Greater abdominal fat accumulation is associated with higher metabolic risk in Chinese than in white people: an ethnicity study. PLoS One. 2013;8(3):e58688. doi: 10.1371/journal.pone.0058688.

5. Wahi G, Anand SS. Race/ethnicity, obesity, and related cardio-metabolic risk factors: a life-course perspective. Curr Cardiovasc Risk Rep. 2013;7:326-35.

6. Lee IK. The prevalence and clinical characteristics of the metabolic syndrome in Korean adults. Korean J Med. 2005;68(4):350-3.

7. Moon OR, Kim NS, Jang SM, Yoon TH, Kim SO. The relationship between body mass index and the prevalence of obesity-related diseases based on the 1995 National Health Interview Survey. Obes Rev. 2002;3(3):191-6.

8. Zhou B, Wu Y, Yang J, Li Y, Zhang H, Zhao L. Overweight is an independent risk factor cardiovascular disease in Chinese populations. Obes Rev. 2002;3(3):143-56.

9. Yaghootkar H, Scott RA, White CC, Zhang W, Speliotes E, Munroe PB, et al. Genetic evidence for a normal-weight "metabolically obese" phenotype linking insulin resistance, hypertension, coronary artery disease, and type 2 diabetes. Diabetes. 2014;63(12):4369-77.

10. Albala BC, Jiménez RB, Pérez BF, Liberman GC. Fatty acid binding protein 2 (FABP-2) polymorphism, obesity and insulin resistance. Rev Med Chil. 2006;134(3):372-9. (In Spanish.)

11. Danforth E Jr, Himms-Hagen JH. Obesity and diabetes and the beta-3 adrenergic receptor. Eur J Endocrinol. 1997;136(4):362-5.

12. Heilbronn LK, Kind KL, Pancewicz E, Morris AM, Noakes M, Clifton PM. Association of $-3826 \mathrm{G}$ variant in uncoupling protein-1 with increased BMI in overweight Australian women. Diabetologia. 2000;43(2):242-4.

13. Leprêtre F, Vionnet N, Budhan S, Dina C, Powell KL, Génin E, et al. Genetic studies of polymorphisms in ten non-insulin-dependent diabetes mellitus candidate genes in Tamil Indians from Pondicherry. Diabetes Metab. 1998;24(3):244-50.

14. Prochazka M, Lillioja S, Tait JF, Knowler WC, Mott DM, Spraul M, et al. Linkage of chromosomal markers on $4 \mathrm{q}$ with a putative gene determining maximal insulin action in Pima Indians. Diabetes. 1993;42(4):514-9.

15. Weiss EP, Brandauer J, Kulaputana O, Ghiu IA, Wohn CR, Phares DA, et al. FABP2 Ala54Thr genotype is associated with glucoregulatory function and lipid oxidation after a high-fat meal in sedentary nondiabetic men and women. Am J Clin Nutr 2007;85(1):102-8.

16. Baier LJ, Sacchettini JC, Knowler WC, Eads J, Paolisso G, Tataranni PA, et al. An amino acid substitution in the human intestinal fatty acid binding protein associated with increased fatty acid binding, increased fat oxidation, and insulin resistance. J Clin Invest. 1995;95(3):1281-7.

17. Lowe JB, Sacchettini JC, Laposata M, McQuillan JJ, Gordon JI. Expression of rat intestinal fatty acid-binding protein in Escherichia coli. Purification and comparison of ligand binding characteristics with that of Escherichia coli-derived rat liver fatty acid-binding protein. J Biol Chem. 1987;262(12):5931-7.

18. Sweetser DA, Birkenmeier EH, Klisak IJ, Zollman S, Sparkes RS, Mohandas T, et al. The human and rodent intestinal fatty acid binding protein genes. A comparative analysis of their structure, expression, and linkage relationships. J Biol Chem. 1987 Nov 25;262(33):16060-71.

19. Yamauchi T, Hara K, Maeda S, Yasuda K, Takahashi A, Horikoshi M, et al. A genome-wide association study in the Japanese population identifies susceptibility loci for type 2 diabetes at UBE2E2 and C2CD4A-C2CD4B. Nat Genet. 2010;42(10):864-8.

20. Zhao T, Zhao J, Yang W. Association of the fatty acid-binding protein 2 gene Ala54Thr polymorphism with insulin resistance and blood glucose: a meta-analysis in 13451 subjects. Diabetes Metab Res Rev. 2010;26(5):357-64.

21. Chiu KC, Chuang LM, Yoon C. The A54T polymorphism at the intestinal fatty acid binding protein 2 is associated with insulin resistance in glucose tolerant Caucasians. BMC Genet. 2001;2:7. doi: 10.1186/1471-2156-2-7.

22. Dhiu KC, Chuang LM, Chu A, Yoon C. Fatty acid binding protein 2 and insulin resistance. Eur J Clin Invest. 2001;31(6):521-7.

23. Yamada K, Yuan X, Ishiyama S, Koyama K, Ichikawa F, Koyanagi A, et al. Association between Ala54Thr substitution of the fatty acid-binding protein 2 gene with insulin resistance and intra-abdominal fat thickness in Japanese men. Diabetologia. 1997;40(6):706-10.

24. Kim SG, Kim CH, Yun SK, Yun YI, Kim YH, Nam IS, et al. Polymorphism of the uncoupling protein 1 (UCP-1) gene and fatty acid binding protein 2 (FABP2) gene in korean type 2 diabetic patients. J Korean Diabetes Assoc. 2001 Aug;25(4):262-72. (In Korean.)

25. Yun SK, Kim CH, Kim YS, Byun DW, Suh KI, Yoo MH, et al. Association between FABP2 gene polymorphism and energy metabolism in normal Korean. J Korean Diabetes Assoc. 1998 Dec;22(4):457-66. (In Korean.)

26. Marín C, Pérez-Jiménez F, Gómez P, Delgado J, Paniagua JA, Lozano A, et al. The Ala54Thr polymorphism of the fatty acid-binding protein 2 gene is associated with a change in insulin sensitivity after a change in the type of dietary fat. Am J Clin Nutr. 2005;82(1):196-200.

27. Medici G, Mussi C, Fantuzzi AL, Malavolti M, Albertazzi A, Bedogni G. Accuracy of eight-polar bioelectrical impedance analysis for the assessment of total and appendicular body composition in peritoneal dialysis patients. Eur J Clin Nutr 2005;59(8):932-7.

28. Woodrow G, Devine Y, Cullen M, Lindley E. Application of bioelectrical impedance to clinical assessment of body composition in peritoneal dialysis. Perit Dial Int. 2007;27(5):496-502.

29. Fosbøl MØ, Zerahn B. Contemporary methods of body composition measurement. Clin Physiol Funct Imaging. 2015;35(2):81-97.

30. Naboush A, Hamdy O. Measuring visceral and hepatic fat in clinical practice and clinical research. Endocr Pract. 2013;19(4):587-9.

31. Friedewald WT, Levy RI, Fredrickson DS. Estimation of the concentration of low-density lipoprotein cholesterol in plasma, without use of the preparative ultracentrifuge. Clin Chem. 1972;18(6):499-502.

32. Fujibayashi K, Yokokawa H, Gunji T, Sasabe N, Okumura M, Ijjima K, et al. Utility of 75-g oral glucose tolerance test results and hemoglobin a1c values for predicting the incidence of diabetes mellitus among middleaged Japanese men -a large-scale retrospective cohort study performed at a single hospital. Intern Med. 2015;54(7):717-23.

33. Pruessner JC, Kirschbaum C, Meinlschmid G, Hellhammer DH. Two formulas for computation of the area under the curve represent measures of total hormone concentration versus time-dependent change. Psychoneuroendocrinology. 2003;28(7):916-31.

34. Gutch M, Kumar S, Razi SM, Gupta KK, Gupta A. Assessment of insulin sensitivity/resistance. Indian J Endocrinol Metab. 2015;19(1):160-4.

35. Bruce RA. Multi-stage treadmill tests of maximal and submaximal exercise. In: American Heart Association Committee on Exercise. Exercise testing and training of apparently healthy individuals: a handbook for physicians. New York: American Heart Association; 1972.

36. Gulati M, McBride PE. Functional capacity and cardiovascular assessment: submaximal exercise testing and hidden candidates for pharmacologic stress. Am J Cardiol. 2005;96(8A): 11-9. 
37. Heyward VH, Gibson AL. Advanced fitness assessment and exercise prescription. 7th ed. Champaign, IL: Human Kinetics; 2014.

38. Damcott CM, Feingold E, Moffett SP, Barmada MM, Marshall JA, Hamman RF, et al. Variation in the FABP2 promoter alters transcriptional activity and is associated with body composition and plasma lipid levels. Hum Genet. 2003;112(5-6):610-6.

39. Levy E, Ménard D, Delvin E, Stan S, Mitchell G, Lambert M, et al. The polymorphism at codon 54 of the FABP2 gene increases fat absorption in human intestinal explants. J Biol Chem. 2001;276(43):39679-84.

40. Hegele RA, Harris SB, Hanley AJ, Sadikian S, Connelly PW, Zinman B. Genetic variation of intestinal fatty acid-binding protein associated with variation in body mass in aboriginal Canadians. J Clin Endocrinol Metab. 1996;81(12):4334-7.

41. Takakura Y, Yoshioka K, Umekawa T, Kogure A, Toda H, Yoshikawa T, et al. Thr54 allele of the FABP2 gene affects resting metabolic rate and visceral obesity. Diabetes Res Clin Pract. 2005;67(1):36-42.

42. Albala C, Santos JL, Cifuentes M, Villarroel AC, Lera L, Liberman C, et al. Intestinal FABP2 A54T polymorphism: association with insulin resistance and obesity in women. Obes Res. 2004;12(2):340-5.

43. Kim CH, Yun SK, Byun DW, Yoo MH, Lee KU, Suh KI. Codon 54 polymorphism of the fatty acid binding protein 2 gene is associated with increased fat oxidation and hyperinsulinemia, but not with intestinal fatty acid absorption in Korean men. Metabolism. 2001;50(4):473-6.

44. Weiss EP, Brown MD, Shuldiner AR, Hagberg JM. Fatty acid binding protein-2 gene variants and insulin resistance: gene and gene-environment interaction effects. Physiol Genomics. 2002;10(3):145-57.
45. Kenchaiah S, Evans JC, Levy D, Wilson PW, Benjamin EJ, Larson MG, et al. Obesity and the risk of heart failure. N Engl J Med. 2002;347(5):30513.

46. Lau DC, Dhillon B, Yan H, Szmitko PE, Verma S. Adipokines: molecular links between obesity and atheroslcerosis. Am J Physiol Heart Circ Physiol. 2005;288(5):H2031-41.

47. Georgopoulos A, Bloomfield H, Collins D, Brousseau ME, Ordovas JM, O'Connor JJ, et al. Codon 54 polymorphism of the fatty acid binding protein (FABP) 2 gene is associated with increased cardiovascular risk in the dyslipidemic diabetic participants of the Veterans Affairs HDL intervention trial (VA-HIT). Atherosclerosis. 2007;194(1):169-74.

48. Mitchell BD, Kammerer CM, O'Connell P, Harrison CR, Manire M, Shipman $\mathrm{P}$, et al. Evidence for linkage of postchallenge insulin levels with intestinal fatty acid-binding protein (FABP2) in Mexican-Americans. Diabetes. 1995;44(9):1046-53.

49. Humphreys P, McCarthy M, Tuomilehto J, Tuomilehto-Wolf E, Stratton I, Morgan R, et al. Chromosome 4q locus associated with insulin resistance in Pima Indians. Studies in three European NIDDM populations. Diabetes. 1994;43(6):800-4

50. Sipiläinen R, Uusitupa M, Heikkinen S, Rissanen A, Laakso M. Variants in the human intestinal fatty acid binding protein 2 gene in obese subject. J Clin Endocrinol Metab. 1997; 82(8):2629-32.

Received February 17, 2017 Accepted in revised form September 10, 2018 